\title{
Dressing of Hybrid Bond CBN Wheels Using Short-Pulse Fiber Laser
}

\author{
Mohammad Rabiey1,* - Christian Walter ${ }^{2}$ - Friedrich Kuster ${ }^{2}-$ \\ Josef Stirnimann ${ }^{1}$ - Frank Pude ${ }^{1}$ - Konrad Wegener ${ }^{1,2}$ \\ 1 inspire AG, ETH Zurich, Switzerland \\ 2 IWF, ETH Zurich, Switzerland
}

\begin{abstract}
A systematic research analysis has been applied to study the effect of dressing parameters on grinding forces, work piece roughness and wheel wear of a hybrid bond CBN grinding wheel. This paper presents some of the results achieved by the comparison between a conventional SiC dressed wheel and a grinding wheel dressed by means of a short-pulse fiber laser. The results show high technological potential for the laser dressing method compared to conventional dressing. Lower grinding forces and specific energy, with relatively the same surface roughness and lower total grinding wear (wear by dressing plus wear by grinding) are the biggest advantages of the laser dressing method over the conventional method. However, the economic aspects of laser dressing (investment on laser source and associated add-ons) at the moment, cannot justify the integration of such systems on the grinding machine for all types of applications. The next challenge is optimization of the laser dressing process to increase the efficiency of the process and expand the possible applications both from a technical and commercial point of view.
\end{abstract}

Keywords: Laser, Dressing, Grinding, Conditioning, CBN, Hybrid bond

\section{O INTRODUCTION}

Hybrid bound grinding wheels, as a newly developed bonding system, have great potential in industrial applications since they combine the advantages of both a metal bond (low wear and high-strength) and a vitrified bond (porosity and good chip pockets) [1] and [2]. However, the problem of dressing such highstrength bonds, which is also characteristic of metal bond wheels, has yet to be effectively and efficiently solved. Currently, to condition hybrid bond wheels, a conventional mechanical dressing process with a $\mathrm{SiC}$ wheel is used. Laser dressing seems to be an appropriate alternative dressing method.

Dressing using a laser can be categorized by two main types of processes. The first is laser dressing whereby the laser beam without using any other dressing tool is applied to the surface of the grinding wheel (tangentially, radially or at an angle) and dresses the wheel [3]. The second method is laser assisted dressing in which the laser beam is applied to the grinding wheel to locally heat up the wheel thereby reducing the strength of the bond and simultaneously removing material by means of a conventional dressing tool [4]. In this research, the first method has been used.

\section{LASER DRESSING, STATE OF THE ART}

The application of laser for dressing of Aluminum Oxid was firstly reported from IIT in 1989. Babu et al [5] and [6] investigated on the effect of Nd: YAG laser on $\mathrm{Al} 2 \mathrm{O} 3$ and $\mathrm{SiC}$ grains, vitrified bond grinding wheel. The laser beam was applied radially to the grinding wheel. The preliminary study showed craters formed by the laser irradiation which were surrounded by a resolidified layer exhibiting multiple cracks. The damages have a direct relation with laser intensities.

Laser technology for conditioning of superabrasives was first proposed by Westkaemper [7] for dressing and truing of resin bond $\mathrm{CBN}$ grinding wheels. The results show diamond topographies with sufficient chip clearance compared to conventional dressing methods. Timmer [3] utilized a Nd:YAG laser to dress diamond and CBN grinding wheels of different bond types, both radially and tangentially to the wheel surface. Kang et al [8] conducted a study of truing resin and metal bond diamond wheels by utilizing pulsed Nd:YAG laser radiation tangentially to the grinding wheel surface. It was observed that the resin bond material started to decompose, the bronze bond either melted or vaporized, and the slightly damaged diamond grains were removed due to sputtering effects of the bond material. Yung et al. [9] used an acousto-optical Q-switched Nd:YAG laser to dress a resin bond CBN wheel. A 10 to $15 \%$ reduction in grinding force compared to conventional dressing as well as good topography of the wheel without destroying or damaging the $\mathrm{CBN}$ grains was reported. Furthermore, the Q-switched laser showed a lower heat accumulation on the wheel surface than continuous wave laser processing. Hosokawa [10] also used Nd:YAG laser radiation and reported successful dressing of metal bond wheels. By precise control of the laser parameters and wheel rotation speed, the appropriate grain protrusion height can be 
generated. Detectable damage to diamond particles, such as micro-cracks or graphitization was not observed below a critical laser power setting. Kunidea et al. [11] used the third harmonic wavelength of a $\mathrm{Nd}$ :YAG laser for conditioning of ultrafine grit resin bond diamond wheels. This resulted in a higher cutting edge density compared to wheels treated using a conventional conditioning method with a cup truer. Chen et al. [12] used an acousto-optical Q-switched $\mathrm{Nd}$ :YAG laser for the conditioning of bronze bond diamond wheels.

\section{EXPERIMENTAL CONDITIONS}

Grinding experiments are carried out with a series of hybrid bond CBN grinding wheels $\left(d_{\text {wheel }}=150 \mathrm{~mm}\right.$, $b=25 \mathrm{~mm}$ ) having an average grain size of $126 \mu \mathrm{m}$ on a commercial surface grinding machine tool. The work piece is hardened steel type $100 \mathrm{Cr} 6(100 \times 60 \times 30$ $\mathrm{mm}$ ) with a hardness of $60 \mathrm{HCR}$.

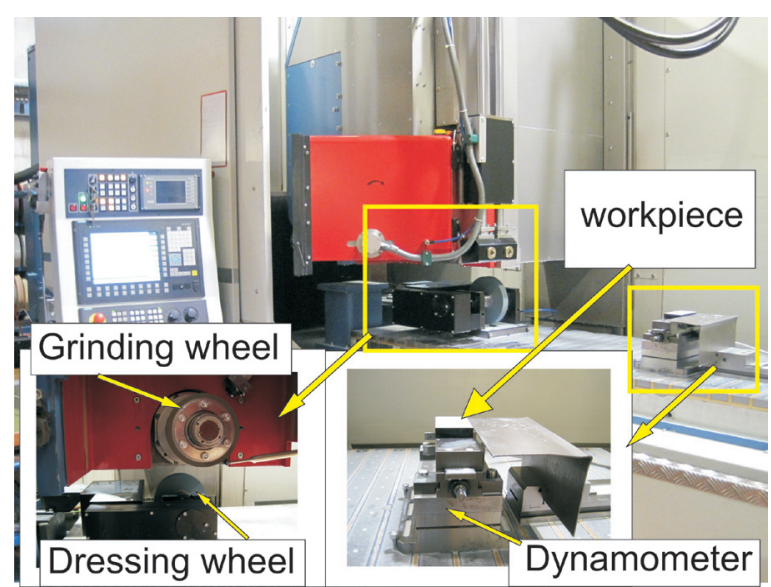

Fig. 1. Setup and machine tool for grinding and conventional dressing experiments

A dynamometer (Kistler, type: 9256B) is mounted under the clamping system of the work piece to measure the tangential force $F_{t}$ as well as normal force $F_{n}$ during the grinding operation. An emulsion $(3 \%)$ with a pressure of 10 bar is used as a cooling lubricant. Fig. 1 shows the experimental setup for grinding and conventional dressing.

\subsection{SiC Dressing}

Conventional dressing experiments are carried out by means of a vitrified $\mathrm{SiC}$ wheel $\left(d_{\text {wheel }}=200 \mathrm{~mm}\right.$, $b=30 \mathrm{~mm}$ ) with the specification 31C-100-L-11310-V138-12. Table 1 shows the selected dressing parameters used in the experiments. In this case, $(+)$ means down dressing. The total depth of dressing set on the machine for each dressing experiments is 100 $\mu \mathrm{m}$. The wear of the grinding wheel and the dressing wheel is measured after each dressing process. The wear of the $\mathrm{CBN}$ wheels after this dressing operation is about $30 \mu \mathrm{m}$. The wear of the $\mathrm{SiC}$ wheel is about $70 \mu \mathrm{m}$.

Table 1. Dressing parameters for experiments

\begin{tabular}{lc}
\hline Dressing Parameters & \\
\hline Dressing speed ratio & +4 \\
\hline Dressing depth of cut & $10 \mu \mathrm{m}$ \\
\hline Dressing feed rate & $1000 \mathrm{~mm} / \mathrm{min}$ \\
\hline
\end{tabular}

\subsection{Laser Dressing}

A schematic of the setup used for laser dressing experiments is depicted in Fig. 2. The beam source is a commercial Q-switched fiber laser system (11) in a master oscillator-power fiber amplifier (MOPFA) configuration. The system has a maximum output power of $P=50 \mathrm{~W}$ at pulse energies of up to $e_{p}=1 \mathrm{~mJ}$, and a pulse width between $t_{p}=125$ to $150 \mathrm{~ns}$. The emission wavelength of the laser is $\lambda=1064 \mathrm{~nm}$. For beam delivery, a monomode fiber (10) is employed, while the light is collimated by outcoupling optics (5) at the fiber exit. Finally, the beam is focused through the focal lens $(f=150 \mathrm{~mm}$ of a commercial laser processing head (6). The sample wheel (9) is mounted on a precision rotary axis (1) where the rotary speed is controlled via an external power supply (2). The rotary axis and processing head are integrated into a specially designed three-axis machine tool (3). The focal position can be varied by traveling in z-direction. To position the beam on the sample, the entire $\mathrm{C}$-axis is moved by the CNC-axis in the $\mathrm{x}-\mathrm{y}$-plane. The laser ON/OFF and the $x-y-z-m o t i o n$ are controlled by the CNC (13) of the machine, while the setting of the laser parameters is realized via an additional PC (12) connected to the laser. Via the gas inlet (7), assist gas can be fed in the process through a nozzle coaxial to the laser beam. In this study, compressed air at a pressure of $p=5$ bar is used.

The diameter of the nozzle is $d_{\text {nozzle }}=1 \mathrm{~mm}$ and the focal plane is located $1 \mathrm{~mm}$ in front of the nozzle.

A digital camera (4) is mounted on the laser head to observe the process through the beam path.

Before dressing the actual grinding wheel, the ablation behavior of abrasive grains and bond material is studied on samples of the abrasive layer. For this purpose, the laser system is employed in a different setup according to Fig. 3. 


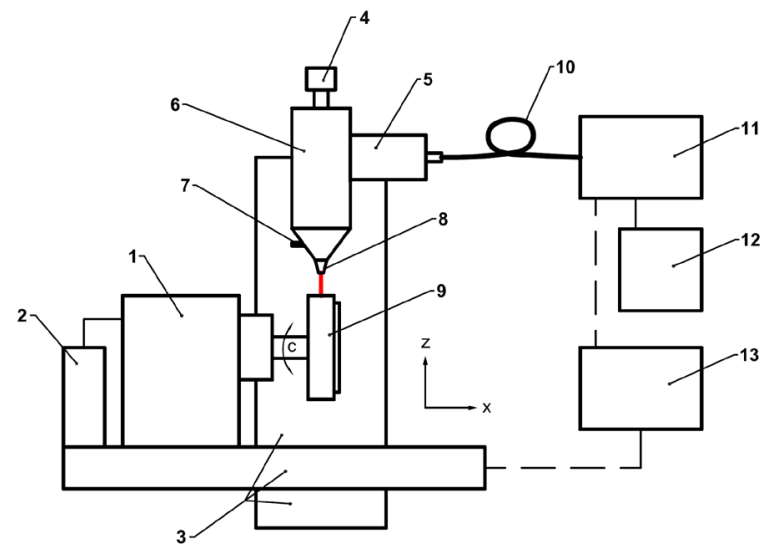

Fig. 2. Setup for the laser dressing experiments (1) rotary axis, (2) power supply, (3) three-axis machine tool, (4) digital camera system, (5) fiber outcoupling optics, (6) laser processing head, (7) assist gas inlet, (8) coaxial nozzle, (9) grinding wheel, (10) laser delivery fiber, (11) laser system, (12) PC and (13) CNC unit

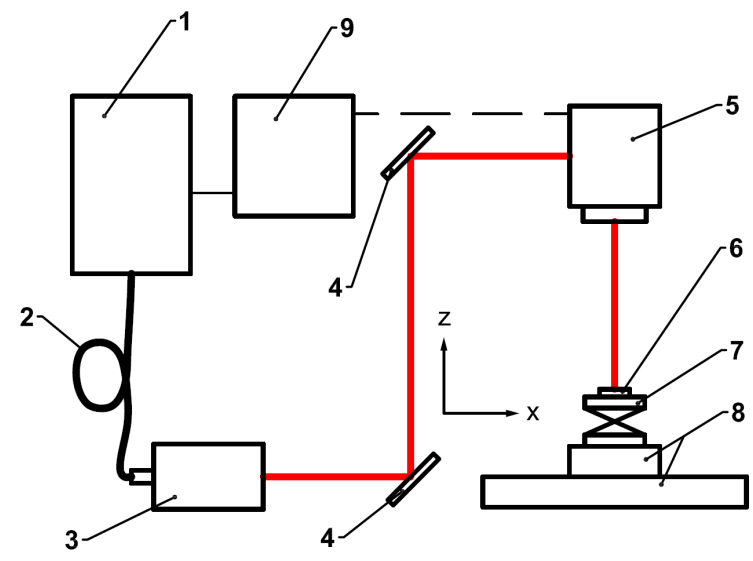

Fig. 3. Setup for laser ablation study (1) laser system, (2) laser delivery fiber, (3) fiber outcoupling optics, (4) mirrors, (5) $x, y$ scanning unit, (6) abrasive layer sample, (7) manual z-axis, (8) x, y motorized linear stages, (9) PC

The sample (6) is placed on a motorized $x-y-$ table (8) combined with a manual z-axis (7) for focal adjustment. The laser beam is deflected on the sample by a $\mathrm{x}$-y scanning unit with a f-theta lens. The ablation is studied by processing reference areas of the abrasive layer with different laser parameters. For the parameter study, laser pulse energy is varied between $e_{p}=0.1$ to $1 \mathrm{~mJ}$, pulse repetition rate between $f_{p}=10$ to $100 \mathrm{kHz}$ and scanning speed between $v_{s}=0.5$ to $5 \mathrm{~m} / \mathrm{s}$. The lowest grinding forces where achieved after laser dressing with an average laser power of $50 \mathrm{~W}$ at $50 \mathrm{kHz}$ pulse repetition frequency.

The processed areas are analyzed by optical 3D microscopy, scanning electron microscopy (SEM) and energy dispersive $\mathrm{X}$-ray spectroscopy (EDX) to find process parameters for a selective ablation of the bond material with low damage of the abrasive grains (Fig. 4).

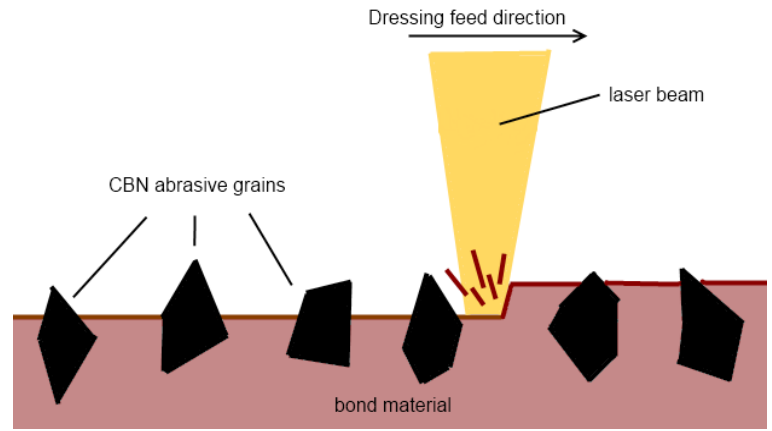

Fig. 4. Principle of laser dressing superabrasive grinding wheels

\subsection{Grinding Conditions}

To compare grinding forces, wear rate and surface roughness of the ground work piece, for both laser dressing and conventional mechanical dressing, the surface grinding parameters indicated in Table 2 are used. All tests are done by down grinding.

Table 2. Grinding parameters for experiments

\begin{tabular}{lc}
\hline Grinding Parameters & \\
\hline Grinding speed & $50 \mathrm{~m} / \mathrm{s}$ \\
\hline Depth of cut & 10 to $300 \mu \mathrm{m}$ \\
\hline Feed rate & 1 to $6 \mathrm{~m} / \mathrm{min}$ \\
\hline
\end{tabular}

The grinding speed is limited to $50 \mathrm{~m} / \mathrm{s}$ due to the small grinding wheel diameter as well as the maximum revolution constraint by the machine spindle. The surface roughness of the ground work pieces are measured by a Taylor-Hobson FormTalysurf roughness tester.

\subsection{Measurement Conditions}

Sinceselective removal of the bond material results in an increase of the surface roughness of the abrasive layer, roughness parameters are used to characterize material removal.

A 3D optical microscope (Alicona Infinite Focus) is utilized to measure the surface topography directly within reference areas of $2 \times 2 \mathrm{~mm}$ before and after laser processing. Furthermore, the topography of the dressed wheels is measured with this system directly and using the replica method.

Due to the complex surface topography (abrasive grains, bond material and pores), not all surface 
parameters are suitable for abrasive layer topography (Figs. 5 and 6). In this study, the arithmetical mean height $\mathrm{Sa}$ and the core roughness depth $S_{k}$ of the surface is used, since these parameters provide information about the roughness amplitude and showed good reproducibility during experimentation [13].

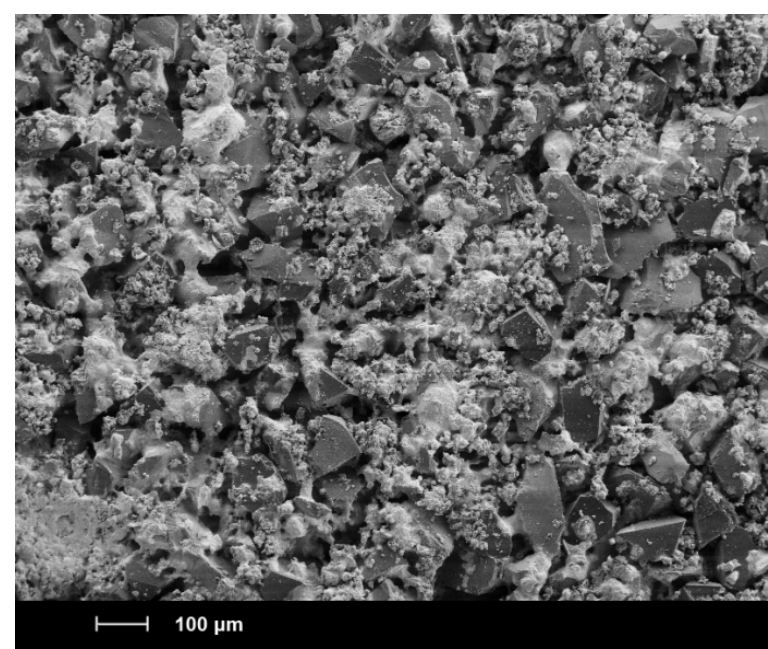

Fig. 5. SEM image of the unprocessed abrasive layer

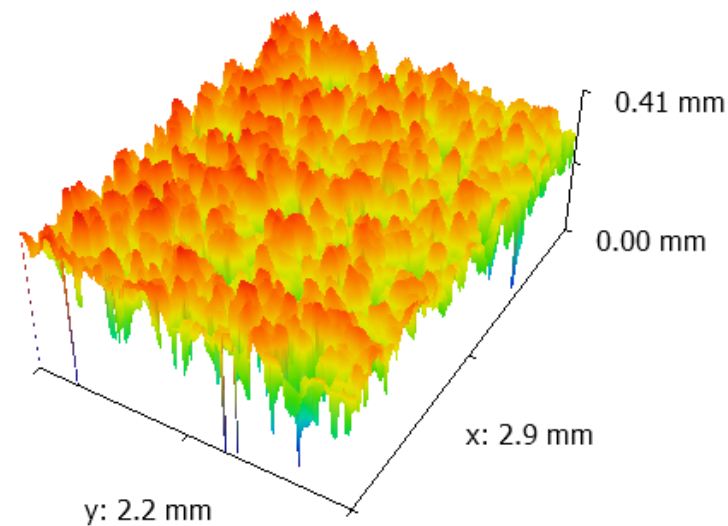

Fig. 6. 3D surface measurement of the laser processed abrasive layer

In the parameter study, the change in roughness values is averaged over five reference areas for each combination of laser parameters that is investigated. Furthermore, SEM imaging is used to analyze the damage of abrasive grains in the processed areas.

For the dressing experiments, the surface roughness of the grinding wheel is measured after each dressing operation at six positions of equal distance on the circumference of the grinding wheel. Additionally, the wheels surface is analyzed with a conventional optical microscope.

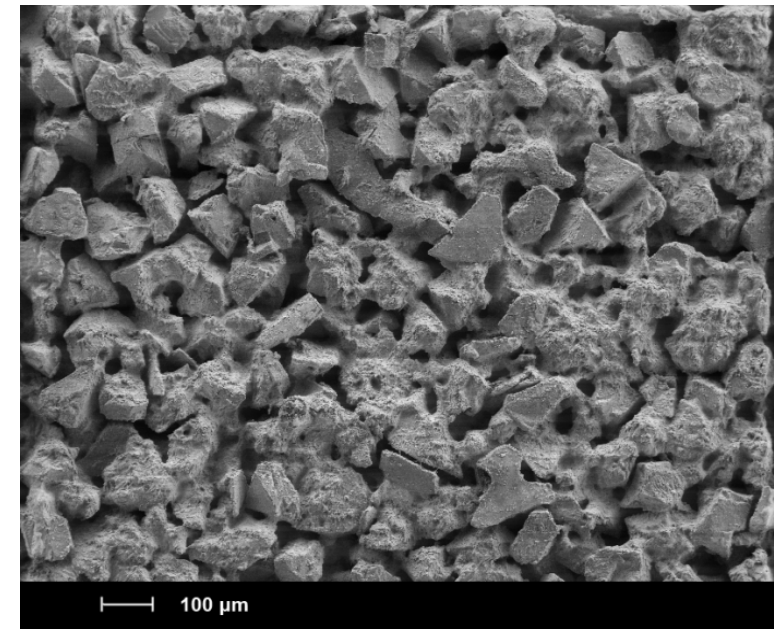

Fig. 7. SEM image of the abrasive layer surface after laser processing ( $t_{p}=125 \mathrm{~ns}, e_{p}=0.6 \mathrm{~mJ}, f_{p}=70 \mathrm{kHz}, v_{s}=2.5 \mathrm{~m} / \mathrm{s}$ )

\section{EXPERIMENTAL RESULTS}

The results of the parameter study confirm that a selective removal of the bond material is possible.

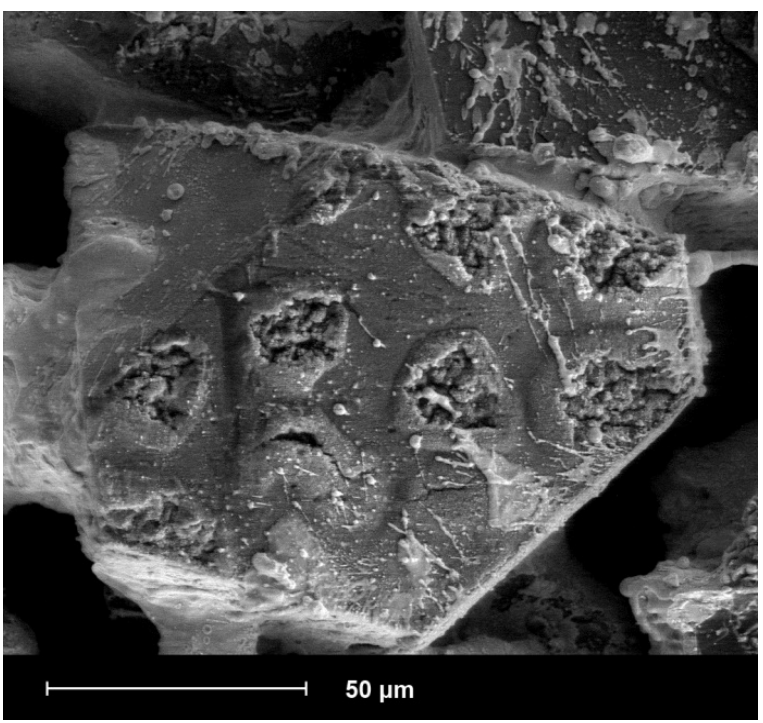

Fig. 8. Laser pulse impact craters on a CBN abrasive grain $\left(t_{p}=125 \mathrm{~ns}, e_{p}=0.5 \mathrm{~mJ}, f_{p}=50 \mathrm{kHz}\right)$

However, for pulse energies above $e_{p}=0.5 \mathrm{~mJ}$, sporadic grain damage is observed on the processed samples (Fig. 8). With increasing pulse energy and increasing pulse overlap, grain damage becomes more evident and frequent.

Since the material removed is relatively small at low pulse energies, laser dressing experiments are carried out at higher pulse energies up to $e_{p}=1$ $\mathrm{mJ}$ to generate a sufficient grain protrusion in only 

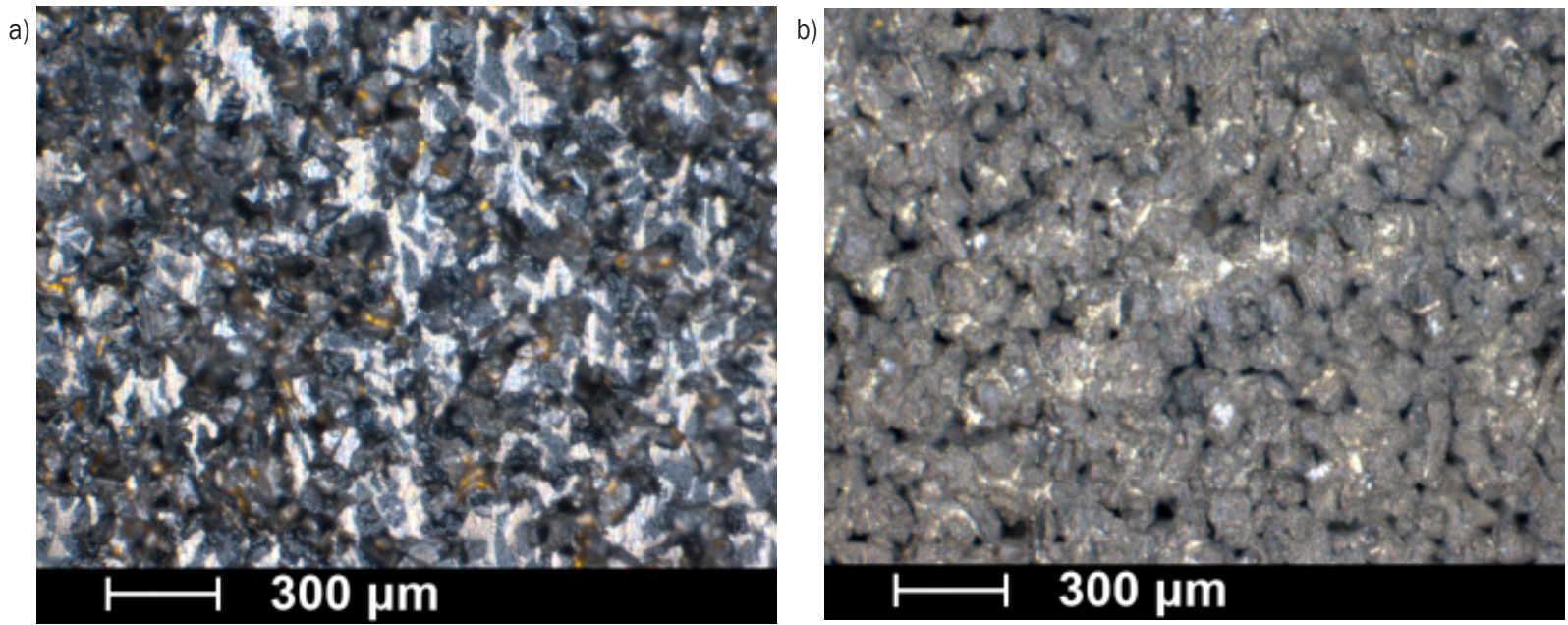

Fig. 9. a) Optical microscope image of conventional SiC dressed, and b) laser dressed grinding wheels surface $\left(t_{p}=150 \mathrm{~ns}, e_{p}=1 \mathrm{~mJ}, f_{p}=50 \mathrm{kHz}, n_{D}=70 / \mathrm{min}\right)$

one dressing pass (Fig. 9). Although increased grain damage on the grinding wheel occurs in this case, grinding experiments do not reflect a negative effect in terms of grinding forces and wheel wear.

By comparing the grinding forces of both conventional and laser dressed wheel by grinding the material 100Cr6 (60 HRC), it is possible to evaluate the grinding performance and efficiency of the process. Fig. 10 shows the effect of increasing the depth of cut on the specific tangential and normal grinding forces for conventional and laser dressed wheel with constant feed rate and grinding speed. It can be seen that the grinding forces are lower for the laser dressed CBN wheel compared to the conventional dressed wheel. The lower grinding forces may be due to better chip pockets produced by laser ablation on the wheel surface. It is also possible that some of the active CBN grains became flatted during conventional dressing because of direct contact with $\mathrm{SiC}$ grains. These flatted grains cause an increase in force and generate more heat during the process. An investigation on the grain morphology after the conventional dressing as well as laser dressing is still in progress and will be published in the near future.

Fig. 11 demonstrates again the tangential and normal grinding forces, in this case versus feed rate with constant depth of cut and grinding speed. Hereby, the results show lower grinding forces by laser dressed compared to the conventional one.

In both Figs. 10 and 11, it is observed that the difference between the normal forces of laser and conventional dressed wheel is higher than the

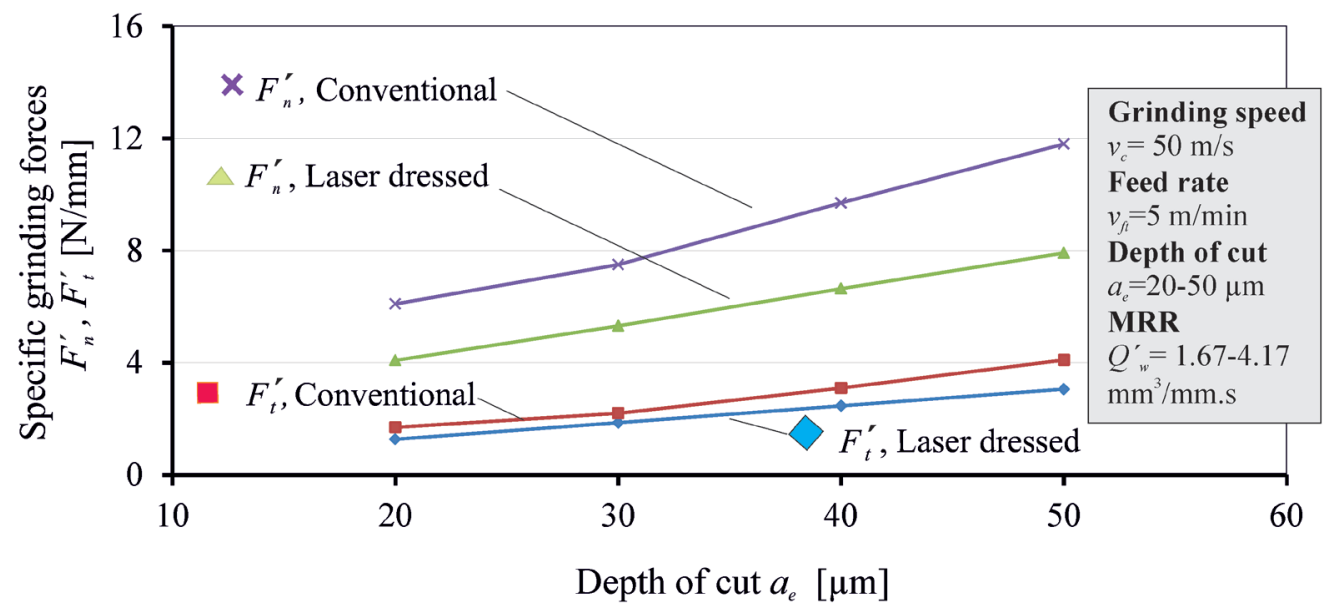

Fig. 10. Specific grinding forces vs. depth of cut by constant feed rate for laser and conventional (SiC) dressed wheel 


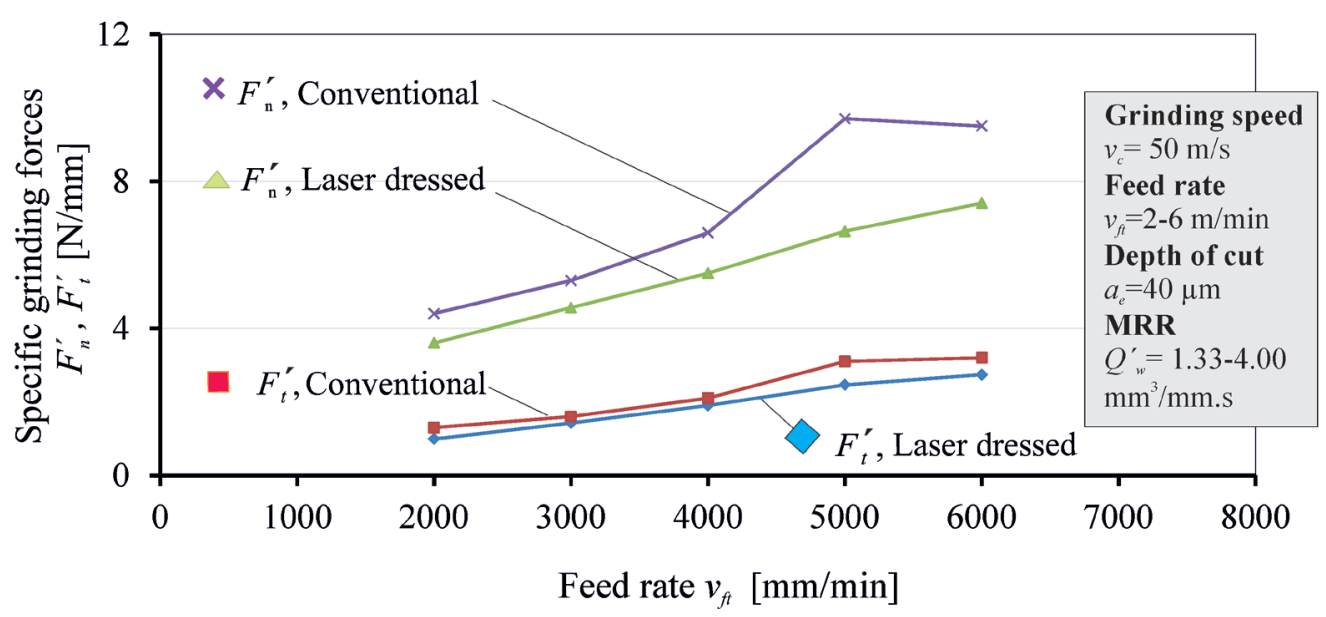

Fig. 11. Specific grinding forces vs. feed rate by constant depth of cut for laser and conventional (SiC) dressed wheel

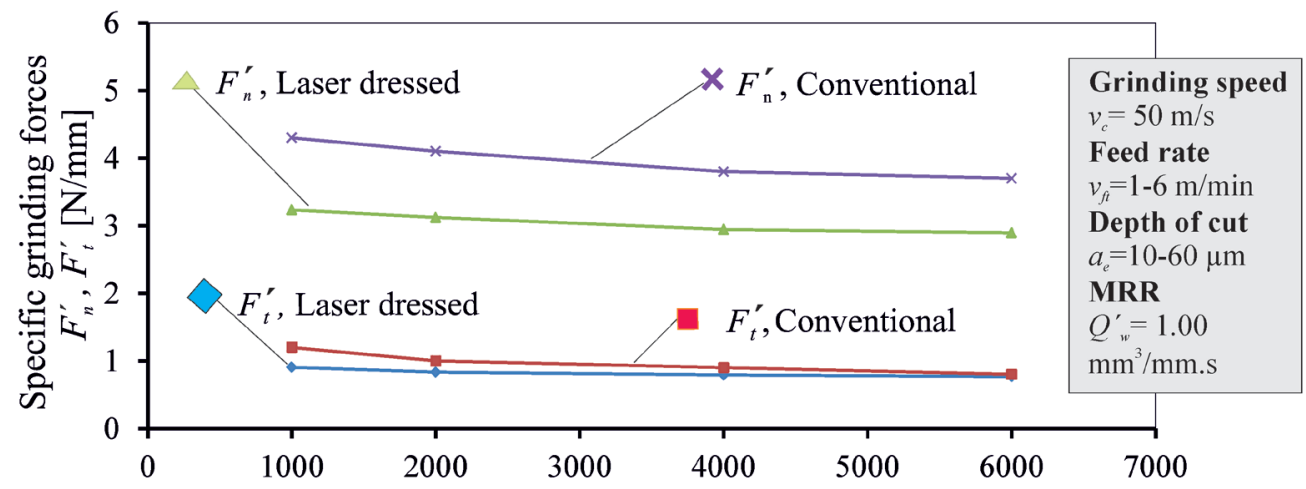

Feed rate $v_{f t}[\mathrm{~mm} / \mathrm{min}]$

Fig. 12. Specific grinding forces vs. feed rate by constant material removal rate for laser and conventional (SiC) dressed wheel

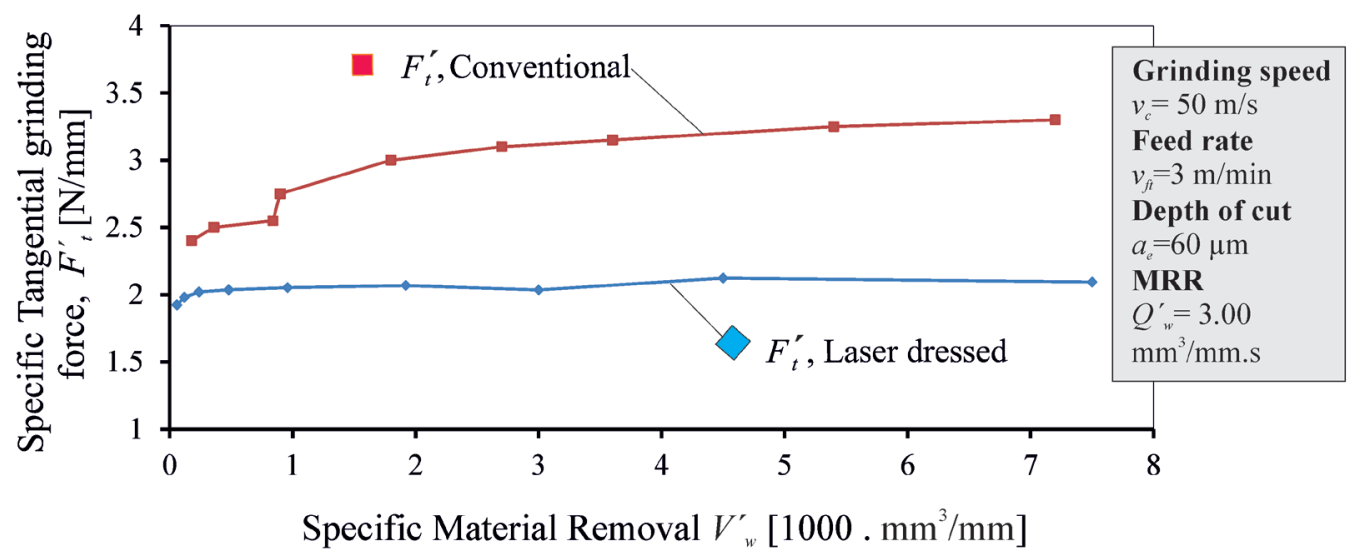

Fig. 13. Specific tangential grinding forces vs. specific material removal for laser and conventional (SiC) dressed wheel

tangential forces which proves the more effective micro-cutting process, and lower micro-plowing and micro-rubbing in case of the laser dressed wheel. As the material removal rate for both cases is the same, the result is a lower specific grinding energy when using the laser dressed wheel.

On the one hand, increasing the feed rate at constant depth of cut and increasing the depth of cut 
at constant feed rate causes an increase in specific grinding forces. On the other hand, the only way to increase the material removal rate is either increasing the depth of cut or feed rate (or both). Fig. 12 shows the grinding forces at constant material removal rate. With increasing feed rate, the depth of cut is reduced, so that a constant material removal rate is achieved. It can be seen that with higher feed rate and lower depth of cut, lower grinding forces are measured. A large difference between the normal forces of conventional and laser dressed wheel is evident, however, only little difference between tangential grinding forces is observed.

Fig. 13 illustrates the change in the specific tangential grinding force with increasing specific material removal. These experiments are used to find the specific material removal after which dressing of the wheel may be necessary. It can be seen that the tangential grinding forces of the laser dressed wheel remain lower than tangential grinding force of the conventional dressed wheel. This shows lower heat generation and good long-term stability of grinding conditions for the laser dressed wheel.

Fig. 14 shows the wear of the laser and conventional dressed grinding wheels under the same grinding conditions, where the specific material removal is increased. A higher radial wear of the laser dressed wheel can be seen in comparison to the conventional dressed wheel. The radial wear rate for both dressing methods in the beginning is rather high, while it then stabilizes at an almost constant rate with increasing specific material removal. It is important to mention that by laser dressing, the maximum radial wear of $15 \mu \mathrm{m}$ (depth of cut by laser) is applied to the $\mathrm{CBN}$ grinding wheel. Compared to the $30 \mu \mathrm{m}$ radial wear by dressing using $\mathrm{SiC}$ wheel, the total wear rate of laser dressed wheel (dressing and grinding) is still lower than for conventional dressed wheel.

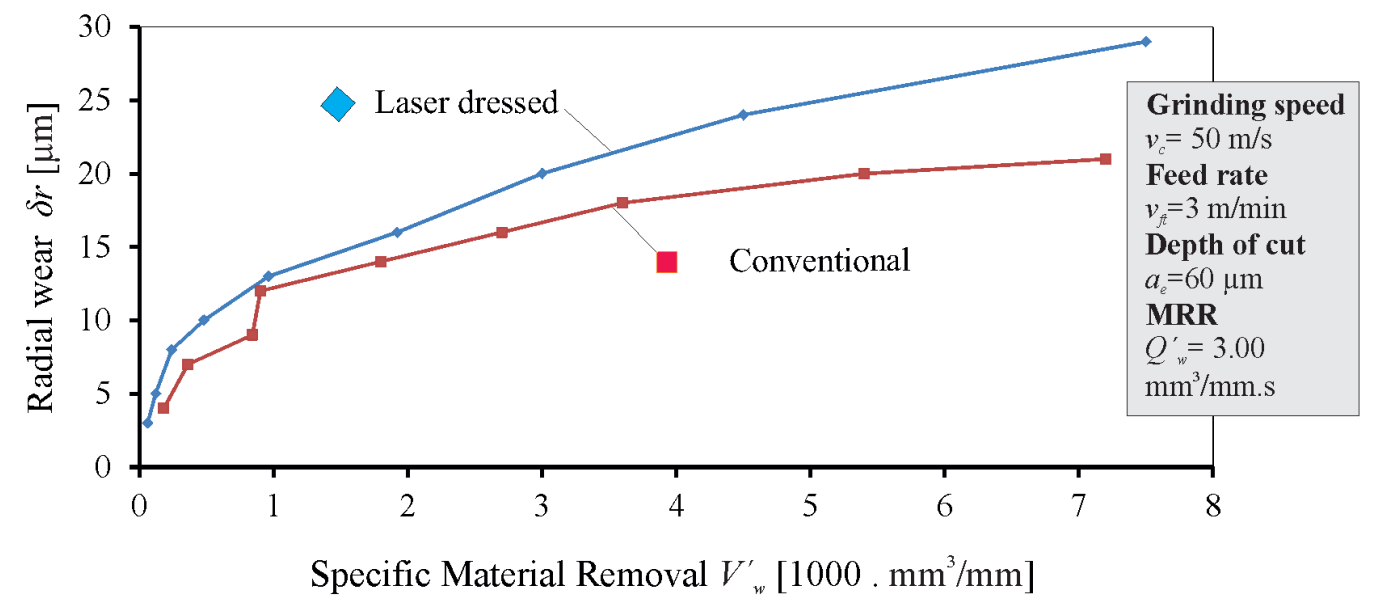

Fig. 14. Radial wheel wear vs. specific material removal for laser and conventional (SiC) dressed wheel

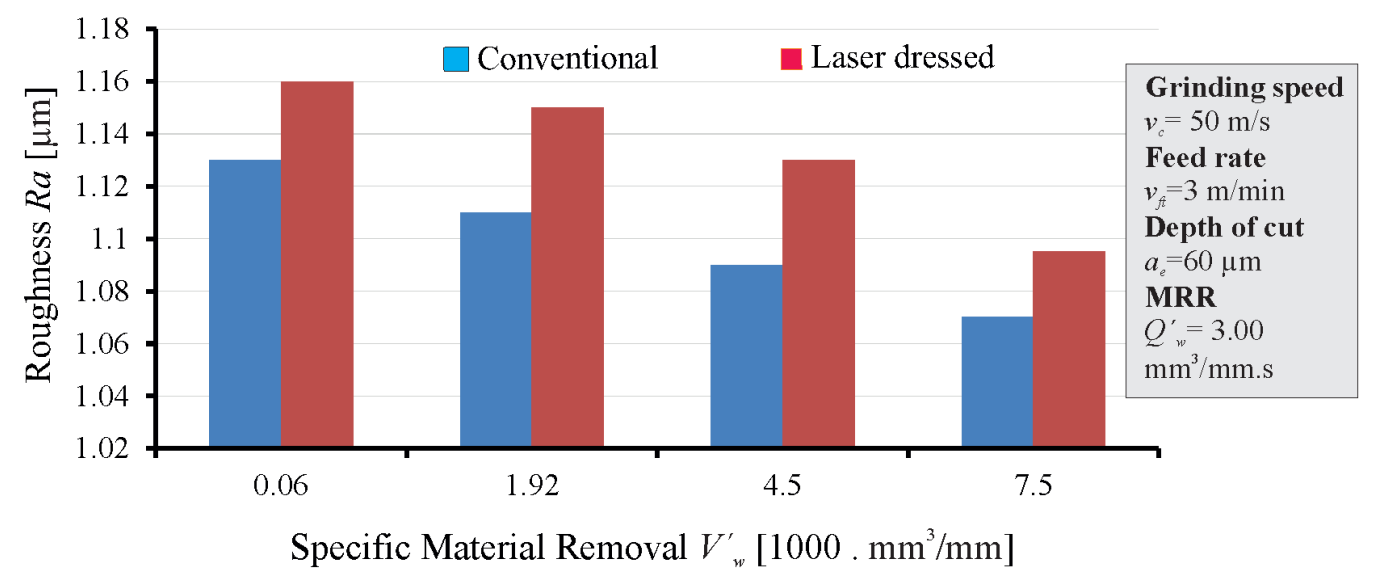

Fig. 15. Surface roughness of ground work piece vs. specific material removal for laser and conventional (SiC) dressed wheel 
Considering the results in Figs. 13 and 14, the reason for higher wear in grinding with the laser dressed wheel can be interpreted by a higher self-sharpening effect. However, more research is necessary to confirm this interpretation of the results.

Fig. 15 shows a comparison of the surface roughness of the ground work piece for a laser and conventional dressed grinding wheel. It can be seen that the work piece surface roughness $\mathrm{Ra}$ with the laser dressed wheel is slightly higher than with the conventional dressed wheel. However, the difference is negligible for most practical applications as it is less than $0.05 \mu \mathrm{m}$. Therefore, it can be stated that with laser dressed grinding wheels, it is possible to produce parts and components with comparable surface quality to the parts ground with conventional dressed wheel, while significantly lowering grinding forces.

\section{CONCLUSION}

The potential of laser dressing of the hybrid bond wheel is shown for high productive grinding. The hybrid bond can be dressed by laser without any negative effects on the cutting performance of the $\mathrm{CBN}$ grits.

Generally, lower grinding forces and consequently lower specific energy and heat generation result from dressing with a laser compared to dressing with $\mathrm{SiC}$. For laser dressing, no wear of the dressing tool has to be considered. These are the most important advantages of the laser dressing method. However, a higher wear of the grinding wheel by grinding and higher surface roughness of ground surface should be taken into account. A reasonable efficiency as well as an effective and reliable laser dressing process can be achieved using a proper process parameter set. More investigations need to be done to study the effect of different laser parameters on the efficiency and quality of the dressing process. The economic aspect of using laser dressing in terms of capital investment of the apparatus and dressing time have to be precisely evaluated. This is the next step which is under investigation. The advantages of the laser method must justify the increase in capital investment and related technical matter of integration of the laser system into a grinding machine.

\section{ACKNOWLEDGMENT}

The authors wish to gratefully acknowledge the financial support which was granted by the Swiss Innovation Promotion Agency as well as the technical support provided by Meister Abrasives AG (Andelfingen), Mägerler AG (Fehraltdorf), and Lasag AG (Thun), all located in Switzerland.

\section{REFERENCES}

[1] Beyer, P. (2005). HPB technology for Vit CBN grinding tools. Industrial Diamond Review, vol. 1, p. 46-48.

[2] Beyer, P. (2005). vDD technology for Vitrified bond diamond dressers. Industrial Diamond Review, vol. 2, p. 34-39.

[3] Timmer, J.H. (2001). Laserkonditionieren von CBNund Diamant-Schleifscheiben. Doctoral Dissertation, Braunschweig University, Braunschweig.

[4] Jackson, M.J., Robinson, G.M., Dahotre, N.B., Khangar, A., Moss, R. (2003). Laser dressing of vitrified aluminium oxide grinding wheels. British Ceramic Transactions, vol. 102, no. 6, p. 237-245, DOI:10.1179/096797803225009346.

[5] Babu, N.R., Radhakrishnan, V., Murti, Y.V. (1989). Investigations on laser dressing of grinding wheels-Part I: Preliminary study, Transaction of ASME, vol. 111, p. 244-252, DOI:10.1115/1.3188756.

[6] Babu, N.R., Radhakrishnan, V. (1989). Investigations on laser dressing of grinding wheels-Part II: Grinding performance of a laser dressed aluminum oxide wheel. Transaction of ASME, vol. 111, p. 253-261, DOI:10.1115/1.3188757.

[7] Westkaemper, E. (1994). Grinding assisted by Nd:YAG Laser. Annals of the CIRP, vol. 44, p. 317-320, DOI:10.1016/S0007-8506(07)62333-6.

[8] Kang, R.K., Yuan, J.T., Zhang, Y.P., Ren, J.X. (2001). Truing of diamond wheels by Laser. Key Engineering Materials, vol. 202-203, p. 137-142, DOI:10.4028/ www.scientific.net/KEM.202-203.137.

[9] Yung, K.C., Chen, G.Y., Li, L.J. (2003). The laser dressing of resin-bonded CBN wheels by a Q-switched Nd:YAG laser. International Journal of advanced Manufacturing, vol. 22, p. 541-546.

[10] Hosokawa, A., Ueda, T., Yunoki, T. (2006). Laser dressing of metal bonded diamond wheel. Annals of the CIRP, vol. 55, no. 1, p. 329-332, DOI:10.1016/S00078506(07)60428-4.

[11] Kunidea, Y., Matsuura, H., Kodama, S., Yoshihara, N., Yan, J., Kuriyagawa, T. (2006). Development of a new laser conditioning method for ultra-fine grit diamond wheels. Key Engineering Materials, vol. 329, p. 175180, DOI:10.4028/www.scientific.net/KEM.329.175.

[12] Chen, G., Mei, L., Zhang, B., Yu, C., Shun, K. (2010). Experiment and numerical simulation study on laser truing and dressing of bronze-bonded diamond wheel. Optics and Lasers in Engineering, vol. 48, no. 3, p. 295-304, DOI:10.1016/j.optlaseng.2009.11.006.

[13] Blunt, L., Jiang, X. (2003). Advanced techniques for assessment surface topography. Elsevier Science \& Technology, p. 19-62. 